\title{
MERUBAH SIKAP TERHADAP BUANG AIR BESAR SEMBARANGAN MELALUI PROGRAM PEMICUAN : KEBIJAKAN NASIONAL
}

\author{
Vera Yulyani ${ }^{1}$, Christin Angelina Febriani ${ }^{1}$, Lolita Sary ${ }^{1}$, Desna Damayanti ${ }^{2}$ \\ Email: vera.yulyani@malahayati.ac.id
}

\begin{abstract}
ABSTRAK
Perilaku buang air besar terbuka (BABS) masih menjadi masalah besar di Indonesia. Di daerah pedesaan perilaku ini masih umum, salah satunya di Desa Bumiharjo, Lampung Timur pada tahun 2016, perilaku BABS masih dilakukan oleh 561 kepala keluarga. Kementerian Kesehatan telah meluncurkan program Sanitasi Total Berbasis Masyarakat (STBM) dengan pendekatan pemicu yang pilar pertamanya adalah Open Defecation Free (ODF). Program ini belum sepenuhnya dilaksanakan di desa. Oleh karena itu, penelitian ini bertujuan untuk mengetahui penerapan program pemicu STBM terhadap perubahan sikap masyarakat tentang buang air besar sembarangan. Jenis penelitian ini adalah kuantitatif dengan desain penelitian eksperimen semu. Hasil penelitian menunjukkan program pemicu memiliki pengaruh pada perubahan sikap masyarakat terhadap BABS $(p=0,002)$. Berdasarkan hasil penelitian ini, kebijakan STBM nasional dengan konsep pemicu harus terus dilaksanakan sampai ODF Village tercapai di seluruh Indonesia.
\end{abstract}

Kata Kunci : perubahan sikap, buang air besar sembarangan, kebijakan nasional

\section{ABSTRACT}

Open defecation behavior (BABS) is still a major problem in Indonesia. In rural areas this behavior is still common, one of which in Bumiharjo Village, East Lampung in 2016, BABS behavior was still carried out by 561 heads of families. The Ministry of Health has launched a Community Based Total Sanitation (STBM) program with a triggering approach whose first pillar is Open Defecation Free (ODF). This program has not been fully implemented in the village. Therefore, this study aims to determine the application of STBM triggering programs to changes in people's attitudes about open defecation. This type of research is quantitative with a quasi experiment research design. The results showed the triggering program had an influence on changes in community attitudes towards BABS $(p=0.002)$. Based on the results of these studies, the national STBM policy with the triggering concept must continue to be carried out until ODF Village is reached throughout Indonesia.

Keywords : changing attitude, open defecation, national policy

\section{PENDAHULUAN}

Di era modern, diperkirakan 673 juta orang melakukan Open Defecation (OD) (Grojec, 2015; Steele, 2019). Buang air besar membahayakan kesehatan anak-anak dan berkontribusi pada kematian dini (Freeman et al., 2017; Nandi, Megiddo, Ashok, Verma, \& Laxminarayan, 2017). Indonesia adalah negara berpenduduk padat dengan banyak OD baik di perkotaan (37\%) dan daerah pedesaan (43\%) ("Annual Report Indonesia 2015," 2016). Perkembangan teknologi yang pesat tidak sejalan dengan peningkatan akses ke sanitasi (WHO, 2016).

Perbedaan karakteristik buang air besar terbuka terjadi di komunitas pedesaan dibandingkan dengan komunitas perkotaan. Penelitian sebelumnya telah menunjukkan bahwa mayoritas penduduk desa melakukan buang air besar sembarangan sebagai akibat dari kurangnya kesadaran publik tentang pentingnya menggunakan

1. Fakultas Kesehatan Masyarakat Universitas Malahayati

2. Puskesmas Beringin Raya Kemiling 
jamban (Yulyani, Nuryani, \& Kurnia, 2019). Pemerintah daerah di Indonesia memiliki tanggung jawab utama untuk menyediakan layanan sanitasi. Kepemimpinan, proses penganggaran, keterlibatan masyarakat dan ketersediaan lahan mempengaruhi realisasi sanitasi yang baik (Chong, Abeysuriya, Hidayat, Sulistio, \& Willetts, 2016). Pemerintah Indonesia melalui Kementerian Kesehatan telah mengeluarkan program yang dikenal sebagai Sanitasi Total Berbasis Masyarakat (CBTS), tetapi tanpa strategi dan komitmen pemerintah daerah, akan sulit untuk mencapai peningkatan akses sanitasi (MCA-Indonesia \& Kesehatan, 2015; Novotný, Humňalová, \& Kolomazníková, 2018).

Perilaku Benar Buang Air Besar di

Provinsi Lampung sudah mencapai 88,3\% (Laporan Hasil Riset Kesehatan Dasar (Riskesdas) Indonesia tahun 2018, 2018). Kabupaten Lampung Timur memiliki jumlah tertinggi di Provinsi Lampung yang banyak melakukan Buang Air Besar Sembarangan yakni 142.86 ribu dari 1.14 juta jiwa (Laporan Kemajuan ODF, 2019). Desa Bumiharjo, Kecamatan Batanghari belum terverifikasi ODF dan belum dilakukan pemicuan (Laporan Kemajuan Akses Sanitasi, 2019).

Angka BABS yang tinggi di Desa Bumiharjo disebabkan karena kondisi lingkungan yang memiliki saluran irigasi (tersier) yang dijadikan sebagai tempat BAB. Oleh karenanya Desa Bumiharjo menjadi target utama pelaksanaan pemicuan. Proses pemicuan dengan pendekatan STBM merupakan salah satu rekayasa untuk membentuk sikap dan perilaku. Alasan peneliti meneliti tentang sikap dan perilaku didasarkan pada pertimbangan bahwa secara psikologis sikap dan perilaku adalah tahapan yang saling terkait. Sikap dianggap memiliki intervensi terhadap terbentuknya perilaku. Penentuan lokasi penelitian di Desa Bumiharjo didasarkan pada tingginya kasus BABS di desa tersebut, dimana datanya merupakan data paling tinggi dibandingkan dengan desa lain di Kecamatan Batanghari. Adapun pemicuan sebagai intervensi yang digunakan dalam penelitian ini disesuaikan dengan sedang digalakkannya program pemicuan CLTS di wilayah tersebut, sementara penyuluhan yang sering dilakukan belum memberikan implikasi yang signifikan. Oleh karenanya diharapkan melalui intervensi ini diharapkan dapat diketahui perbandingan efek yang dapat menggambarkan sikap masyarakat tentang BABS sebelum dan setelah dilakukan intervensi. Berdasarkan data diatas, peneliti ingin melihat bagaimana sikap yang terbentuk dari pengaruh intervensi pemicuan stop BABS terhadap perubahan sikap Kepala Keluarga di Desa Bumiharjo Kecamatan Batanghari Kabupaten Lampung Timur.

\section{METODE PENELITIAN}

Jenis penelitian ini adalah kuantitatif dengan pendekatan kuasi eksperimen, pre dan post test design. Penelitian dilakukan di Desa Bumiharjo Kabupaten Lampung Timur dengan sasaran intervensi adalah masyarakat yang masih melakukan Buang Air Besar Sembarangan. Instrumen penelitian menggunakan penelitian sikap yang telah dilakukan uji validitas di Desa $40^{\prime} \mathrm{C}$ Kecamatan Batanghari. Teknik pengambilan sampel adalah non probability sampling dengan kriteria inklusi adalah masyarakat yang masih praktek BABS. Analisis data yang digunakan adalah analisis univariat Analisis univariat dalam penelitian ini digambarkan melalui perolehan nilai rata-rata (mean), nilai tengah (median), nilai minimum dan maksimum serta dan simpangan baku (standar deviasi) sikap remaja, Analisis bivariat menggunakan uji $t$ (uji beda dua rata-rata), dan analisis General linier Model (GLM).

\section{HASIL \\ Deskripsi Sikap Responden}

Berdasarkan tabel di atas menunjukkan perbedaan rata rata sikap yang diukur dari aspek kognitif, afektif, dan konatif pada kelompok intervensi penyuluhan dan kelompok intervensi pemicuan pada KK di Desa Bumiharjo Kecamatan Batanghari Kabupaten Lampung Timur. 
Tabel 1

Pengukuran Sikap Sebelum dan Setelah Diberikan Komunikasi Intensify Repetisi, Asosiasi, Komposisi

\begin{tabular}{|c|c|c|c|c|c|c|c|c|}
\hline \multicolumn{5}{|c|}{ Intervensi Penyuluhan } & \multicolumn{4}{|c|}{ Intervensi Pemicuan } \\
\hline & Mean $(n=30)$ & Med & SD & $\begin{array}{c}\text { Min } \\
\text { Maks }\end{array}$ & Mean $(n=30)$ & Med & SD & $\begin{array}{c}\text { Min } \\
\text { Maks }\end{array}$ \\
\hline \multicolumn{9}{|c|}{ Sikap (Kognitif) } \\
\hline Sebelum & 23,83 & 23,00 & 6,838 & $11-37$ & 22,17 & 22,00 & 6,226 & $12-35$ \\
\hline Setelah & 22,17 & 22,00 & 6,226 & $12-35$ & 26,37 & 26,37 & 5,288 & $17-36$ \\
\hline \multicolumn{9}{|c|}{ Sikap (Afektif) } \\
\hline Sebelum & 22,83 & 22,00 & 6,254 & $14-36$ & 29,47 & 29,50 & 6,699 & $18-40$ \\
\hline Setelah & 29,47 & 29,50 & 6,699 & $18-40$ & 29,07 & 29,50 & 4,218 & $20-37$ \\
\hline \multicolumn{9}{|c|}{ Sikap (Konatif) } \\
\hline Sebelum & & 17,50 & 4,897 & $12-31$ & 27,13 & 26,50 & 6,458 & $15-38$ \\
\hline Setelah & 27,13 & 26,50 & 6,458 & $15-38$ & 24,97 & 24,50 & 6,703 & $15-37$ \\
\hline \multicolumn{9}{|l|}{ Sikap } \\
\hline Sebelum & & 67,00 & 13,297 & $43-88$ & 78,77 & 77,50 & 14,866 & $50-103$ \\
\hline Setelah & 78,77 & 77,50 & 14,866 & $50-103$ & 80,40 & 78,50 & 10,947 & 64-104 \\
\hline
\end{tabular}

\section{Perbedaan Sikap Sebelum dan setelah Intervensi dan Perbedaan sikap Antara Kelompok Intervensi dan Kelompok Kontrol}

Terdapat perbedaan sikap kognitif sebelum dan setelah intervensi penyuluhan dan pemicuan $(p=0,012)$, terdapat perbedaan sikap afektif sebelum dan setelah intervensi penyuluhan dan pemicuan $(p=0,024)$ dan terdapat perbedaan sikap konatif sebelum dan setelah intervensi penyuluhan dan pemicuan $(p=0,047)$ pada Kepala Keluarga tentang Stop BABS di Desa Bumiharjo Kecamatan Batanghari Kabupaten Lampung Timur. Terdapat perbedaan sikap (kognitif, afektif dan konatif) antara kelompok yang mendapatkan intervensi penyuluhan dan pemicuan dengan kelompok kontrol $(p=0,035)$ pada Kepala Keluarga tentang Stop BABS di Desa Bumiharjo Kecamatan Batanghari Kabupaten Lampung Timur.

Ada pengaruh metode penyuluhan dan pemicuan terhadap perubahan sikap Kepala Keluarga tentang Stop BABS di Desa Bumiharjo Kecamatan Batanghari Kabupaten Lampung Timur $(p<0,05)$ artinya terdapat perubahan sikap sebelum dan setelah intervensi penyuluhan dan pemicuan dan terdapat perbedaan sikap antara kelompok intervensi dan kontrol pada Kepala Keluarga tentang Stop BABS di Desa Bumiharjo Kecamatan Batanghari Kabupaten Lampung Timur.

Tabel 2

Perbedaan Sikap Kognitif, Afektif, Konatif per-kelompok Penyuluhan, Pemicuan dan Kontrol

\begin{tabular}{llcc}
\hline \multirow{2}{*}{ Sikap } & \multirow{2}{*}{ Kelompok } & \multicolumn{2}{c}{ Nilai Beda } \\
\cline { 3 - 4 } Kognitif & Selisih Mean (pre-post) & Pv \\
\cline { 3 - 4 } Afektif & Pemiculuhan & 4,07 & 0,021 \\
\multirow{2}{*}{ Konatif } & Penyuluhan & 4,20 & 0,018 \\
& Pemicuan & 4,37 & 0,006 \\
\multirow{2}{*}{ Sikap } & Penyuluhan & 5,40 & 0,001 \\
\multirow{2}{*}{ Sikap } & Penyuluan & 4,17 & 0,005 \\
& Pemicuan & 5,17 & 0,009 \\
& Intervensi & 4,10 & 0,007 \\
& Kontrol & 4,53 & 0,003 \\
\end{tabular}


Berdasarkan Tabel 2, diketahui bahwa intervensi pemicuan memberikan efek paling baik dalam membentuk sikap kognitif $(4,20 ; p v=0,018)$ afektif $(5,40$; $\mathrm{pv}=0,001)$ dan konatif $(5,17 ; \mathrm{pv}=0,009)$ dibandingkan dengan intervensi penyuluhan pada Kepala Keluarga di Desa Bumiharjo Kecamatan Batanghari Kabupaten Lampung Timur. Sikap efektif Kepala keluarga tentang Stop BABS merupakan aspek sikap yang paling besar perubahannya setelah intervensi penyuluhan $(4,37 ; \quad p v=0,006)$ dan pemicuan $\quad(5,40 ; \quad p v=0,001)$ dibandingkan perubahan sikap pada aspek kognitif dan konatif. Intervensi penyuluhan dan pemicuan $(3,63$; $\mathrm{pv}=0,001)$ merupakan intervensi yang memberikan pengaruh perubahan sikap KK yang lebih baik dibandingkan dengan KK yang tidak diberikan intervensi penyuluhan dan pemicuan $(1,97 ; p v=0,037)$.

\section{PEMBAHASAN}

Hasil penelitian menunjukkan ada perubahan perolehan rata rata sikap antara sebelum dilakukan penyuluhan dengan perolehan rata rata sikap setelah dilakukan penyuluhan. Ada perubahan perolehan rata rata sikap responden sebelum dilakukan pemicuan dan setelah dilakukan pemicuan. Perolehan rata rata sikap antara kelompok intervensi dan kelompok kontrol tidak terlalu jauh berbeda. Perbedaan rata rata sikap cukup signifikan antara kelompok intervensi dan kelompok kontrol.

Sikap adalah penilaian seseorang terhadap stimulus atau objek (Crano \& Prislin, 2008). Setelah mengetahui stimulus atau objek seseorang akan mengalami proses yang selanjutnya akan menilai atau bersikap terhadap stimulus atau objek yang dimaksud. Terdapat beberapa faktor yang dapat mempengaruhi sikap seseorang yaitu diantaranya pengalaman, kebudayaan, orang yang dianggap penting, media massa dan lembaga pendidikan dan agama (Azwar, 2013). Responden eksperimen berada dalam satu wilayah dengan karakteristik kebudayaan yang sama, sehingga tidak ada perbedaan karakteristiknya.

Responden akan dapat bersikap baik jika mereka mengetahui, mengerti dan memahami objek secara baik disini yang dimaksudkan adalah mereka mengetahui, mengerti dan memahami tentang risiko BABS terhadap kesehatan, tetapi dapat menjadi sebaliknya jika responden khususnya responden tidak mengetahui tentang Stop BABS, mereka bisa saja bersikap acuh tak acuh terhadap perilaku BABS. Setiap individu memperoleh informasi yang selalu berubah-ubah setiap harinya sesuai dengan kualitas penerimaanya(Csapó \& Magyar, 2010).

Dasar pembentukan sikap, maka hendaknya melalui kesan yang kuat, yang artinya apa yang didapat akan membentuk dan mempengaruhi penghargaan manusia terhadap stimulus sosial(Maulana, 2007). Tanggapan ini lah yang akan menjadi salah satu dasar pembentukan sikap. Banyak penelitian dilakukan dengan cara memberikan informasi secara formal melalui penyuluhan atau pemicuan. Dengan metode tersebut beberapa penelitian menunjukkan hasil yang cukup signifikan terhadap perubahan sikap responden. Diantaranya penelitian oleh Arifah (2016) dimana bahwa penelitian saat dilakukan pretest sebanyak 83 responden $(63,8 \%)$ dikatagorikan cukup dan dikatagorikan baik sebanyak 47 $(36,2 \%)$. Setelah diberikan penyuluhan pendidikan kesehatan kemudian dilakukan posttest meningkat yaitu dikatagorikan cukup menjadi 3 responden $(2,3 \%)$ dan dikatagorikan baik menjadi 127 responden $(97,7 \%)$.

Sikap yang ditempuh oleh seseorang merupakan salah satu faktor akan mendukung kemampuan orang berperilaku (Ekawati, Agustina, Dukabaen, \& Telan, 2017). Individu sikap cenderung memiliki perilaku yang konformis atau searah dengan sikap orang yang dianggapnya penting(Azwar, 2013). Kecenderungan ini antara lain dimotivasi oleh keinginan untuk berafiliasi dan keinginan untuk menghindari konflik dengan orang lain atau kebutuhan personalnya. Berdasarkan di atas pengalaman responden terkait masalah tentang Stop BABS tidak dialami secara langsung namun beberapa menanyakan terkait dengan masalah yang terjadi pada mereka tentang perilaku BABS yang 
banyak dilakukan oleh masyarakat usia sekolah, itu menunjukkan bahwa ada responden yang memiliki sikap yang relatif berbeda.

Berdasarkan penjelasan tersebut maka menurut peneliti perubahan sikap dan perilaku dari individu dapat dilakukan dengan menanamkan prinsip sehat dalam materi penyuluhan dan pemicuan. Penyuluhan kesehatan adalah kegiatan pendidikan kesehatan yang dilakukan dengan cara menyebar pesan, menanamkan keyakinan sehingga masyarakat sadar dan mengerti tetapi juga mau bisa melakukan tindakan yang ada hubungannya dengan kesehatan(Hou, 2014). Tujuan penyuluhan adalah untuk mengubah perilaku yang kurang sehat menjadi sehat. Perilaku kurang tersebut bukan suatu penyakit, tetapi suatu perilaku yang karena kebiasan atau adat atau karena masalah budaya yang lain. Termasuk dalam hal ini tujuan penyuluhan juga untuk merubah perilaku buang air besar dari tidak memenuhi syarat kesehatan menjadi memenuhi syarat kesehatan. Untuk itu diperlukan perubahan perilaku masyarakat untuk $B A B$ di tempat yang memenuhi syarat kesehatan. Sesuai dengan teori yang ada dijelaskan bahwa WC yang memenuhi syarat kesehatan harus tidak mencemari air tanah dan atau air permukaan, jarak dengan sumber air $+10 \mathrm{~m}$, bila berbentuk leher angsa air penyekat selalu menutup lubang tempat jongkok, bila tanpa leher angsa harus dilengkapi dengan penutup lubang tempat jongkok yang dapat mencegah lalat atau serangga/binatang lainnya.

Penyuluhan merupakan salah satu sarana untuk penyebaran informasi, dengan mengikuti penyuluhan maka masyarakat akan mendapatkan informasi yang lengkap tentang kesehatan lingkungan sehingga memotivasi agar tidak melakukan BABS lagi(Sharma \& Romas, 2012). Jika tidak mengikuti penyuluhan maka akan kurang mendapatkan informasi tentang BABS. Akibat tidak pernah mendapatkan informasi ini maka responden tidak mengetahui bahwa buang air besar harus memperhatikan persyaratan kesehatan. Pada akhirnya responden tidak pernah berpikir bahwa buang air besar yang dilakukan harus di jamban atau WC yang tertutup, tidak mencemari air tanah, tidak berbau dan persyaratan lainnya. Tidak adanya pemikiran demikian maka responden juga tidak memiliki sikap positif terhadap upaya buang air besar yang memenuhi syarat kesehatan. Pada akhirnya tidak akan ada motivasi untuk buang air besar di jamban atau WC yang memenuh syarat kesehatan.

Bersumber dari informasi ini maka kognisi responden menjadi bertambah. Kondisi ini pada akhirnya akan berpengaruh terhadap afeksinya yang mendorong pada terbentuknya sikap positif atau sebaliknya perubahan afektif yang menjadi lebih baik. Aspek afektif berkaitan dengan pandanganpandangan atau perasaan yang disertai kecenderungan untuk bertindak sesuai sikap objek tadi. Jika dikaitkan dengan perilaku BABS sedangkan dia sudah memiliki jamban maka perlu dikaji pula bagaimana aspek afektif berkontribusi terhadap perilakunya.

Refleksi sikap tersebut seharusnya menjadi perhatian. Sikap merupakan suatu keadaan internal (internal state) yang mempengaruhi pilihan tidakan individu terhadap beberapa obyek, pribadi, dan peristiwa. Sikap adalah pandangan-pandangan atau perasaan yang disertai kecenderungan untuk bertindak sesuai sikap objek tadi. Struktur sikap menyangkut aspek afektif merupakan perasaan yang menyangkut aspek emosional. Aspek emosional inilah yang biasanya berakar paling dalam sebagai komponen sikap dan merupakan aspek yang paling bertahan terhadap pengaruh-pengaruh yang mungkin adalah mengubah sikap seseorang komponen afektif disamakan dengan perasaan yang dimiliki seseorang terhadap sesuatu.

Hasil penelitian menunjukkan bahwa masih ada masyarakat yang memiliki sikap permisif terhadap perilaku BABS. Data ini juga menggambarkan bagaimana sikap masyarakat terhadap perilaku BABS, namun melihat jumlah masyarakat yang peduli lebih banyak dari masyarakat yang sikapnya tidak peduli. Meskipun sudah memiliki jamban tetapi sebagian besar masih saja 
melakukan BAB di sungai ini menjadi tantangan dalam upaya membertuk perilaku yang mendukung kesehatannya. Data ini memposisikan aspek afektif sebagai salah satu faktor predisposisi yang menjadi alasan masyarakat untuk BAB di jamban keluarga.

Berdasarkan hasil penelitian tersebut maka penulis berpendapat bahwa aspek afektif dapat memberikan efek secara psikologis terhadap perubahan perilaku dalam hal ini adalah melakukan BAB di jamban. Oleh karenanya intervensi promosi kesehatan yang dapat dilakukan adalah memformulasikan bentuk, cara, dan strategi promosi kesehatan yang mengacu pada 3 domain psikologis yaitu perubahan kognitif, perubahan afektif dan perubahan konatif dengan demikian dari pengetahuan yang diperoleh kepala keluarga akan membentuk sikap positif tentang perilaku BAB dan kemudian mendorong kepala keluarga melakukan $B A B$ di jamban untuk kepentingan kesehatan diri dan keluarganya.

$$
\text { Hasil penelitian dengan }
$$

menggunakan paired $\mathrm{t}$ test didapatkan nilai $p=0,001$ sehingga dapat disimpulkan ada pengaruh penyuluhan terhadap perubahan sikap Kepala Keluarga tentang Stop BABS di Desa Bumiharjo Kecamatan Batanghari Kabupaten Lampung Timur. Didapatkan nilai $p=0,005$ pada intervensi pemicuan sehingga dapat disimpulkan ada pengaruh pemicuan terhadap terhadap perubahan sikap Kepala Keluarga tentang Stop BABS di Desa Bumiharjo Kecamatan Batanghari Kabupaten Lampung Timur

Pada kelompok kontrol didapatkan nilai $p=0,471$ sehingga dapat disimpulkan tidak ada pengaruh pemberian informasi tentang stop BABS terhadap perubahan sikap Kepala Keluarga tentang Stop BABS di Desa Bumiharjo Kecamatan Batanghari Kabupaten Lampung Timur. Hasil yang menunjukkan perbedaan sikap antara kelompok kontrol dan kelompok intervensi diketahui dari uji independent $t$ test didapatkan nilai $p=0,001$ sehingga dapat disimpulkan ada perbedaan sikap antara kelompok intervensi dan kelompok kontrol pada Kepala Keluarga tentang Stop BABS di Desa Bumiharjo
Kecamatan Batanghari Kabupaten Lampung Timur

Sikap (attitude) merupakan reaksi atau respon yang masih tertutup dari seseorang terhadap stimulus atau obyek. Dalam penelitian ini, sikap responden yang menjadi objek pengukuran mencakup reaksi atau respon terhadap perilaku BABS. Seperti telah dijelaskan sebelumnya bahwa penyuluhan merupakan upaya memasarkan, menyebarluaskan, mengenalkan, atau menjual kesehatan. Selanjutnya juga dijelaskan bahwa penyuluhan ditujukan untuk mengubah perilaku yang kurang sehat menjadi sehat. Perilaku kurang tersebut bukan suatu penyakit, tetapi suatu perilaku yang karena kebiasan atau adat atau karena masalah budaya yang lain.

Adanya perbedaan sikap sebelum dan sesudah penyuluhan disebabkan karena responden telah mendapatkan informasi dari penyuluhan dan pemicuan sebagai sumber pengetahuannya sehingga pengetahuannya bertambah. Kondisi ini pada akhirnya akan merubah sikapnya sehingga berubah dari sikap negatif menjadi sikap positif. Sikap yang positif paling tidak akan menimbulkan niat untuk melakukannya bahkan menjadi sumber motivasi untuk buang air besar yang memenuhi syarat kesehatan. Dengan adanya perbedaan perilaku diharapkan masyarakat segera membangun jamban keluarga yang memenuhi syarat kesehatan, menggunakannya setiap hari dan meninggalkan kebiasaan lama membuang air besar di sungai atau di tempat lainyang memungkinkan terjadinya pencemaran.

Berdasarkan penjelasan secara konseptual dan bukti empiris tersebut maka penelit menjelaskan bahwa individu dapat menentukan sendiri sesuatu yang bermakna bagi dirinya sendiri, begitu pula tindakan serta cara mencapai tujuan itu. Responden mempunyai kepribadian sendiri dan karena itu mempunyai kemampuan untuk menciptakan sasaran tindakannya. Berfikir merupakan proses pencarian kemungkinan yang bersifat simbolis dan untuk mempelajari tindakan-tindakan yang mungkin mengarah pada dirinya. Melalui proses komunikasi itu responden 
akan belajar untuk menanggapi stimulus yang diterima dengan mengintepretasikannya terlebih dahulu. Responden dapat mengendalikan tindakannya agar dalam proses interaksi tidak merugikan dirinya.

Hasil analisis secara statistik dapat dilihat pada kelompok intervensi terdapat perbedaan sikap sebelum dan setelah penyuluhan $(p=0,001<0,05)$, dan terdapat perbedaan sikap sebelum dan setelah pemicuan $(p=0,001<0,05)$. Tidak terdapat perbedaan yang signifikan rata-rata nilai sikap sebelum penyuluhan dan pemicuan $(p=0,653<0,05)$. Adapun pada kelompok kontrol diketahaui tidak terdapat perbedaan sikap sebelum dan setelah dilakukan pemberian informasi $(p=1,00<0,05)$ pada Kepala Keluarga tentang Stop BABS di Desa Bumiharjo Kecamatan Batanghari Kabupaten Lampung Timur.

Hasil analisis multivariat menunjukkan beberapa kesimpulan bahwa intervensi pemicuan memberikan efek paling baik dalam membentuk sikap kognitif $(4,20 ; p v=0,018)$ afektif $(5,40$; $p v=0,001)$ dan konatif $(5,17 ; p v=0,009)$ dibandingkan dengan intervensi penyuluhan. Sikap efektif Kepala keluarga tentang Stop BABS merupakan aspek sikap yang paling besar perubahannya setelah intervensi penyuluhan $(4,37 ; \quad p v=0,006)$ dan pemicuan $\quad(5,40 ; \quad p v=0,001)$ dibandingkan perubahan sikap pada aspek kognitif dan konatif. Intervensi penyuluhan dan pemicuan $(3,63$; $\mathrm{pv}=0,001)$ merupakan intervensi yang memberikan pengaruh perubahan sikap $\mathrm{KK}$ yang lebih baik dibandingkan dengan KK yang tidak diberikan intervensi penyuluhan dan pemicuan $(1,97 ; p v=0,037)$.

Hasil tersebut menunjukkan bahwa dalam proses penyuluhan dan pemicuan aspek sikap yang dominan terbentuk adalah aspek afektif, oleh sebab itu dalam pelaksanaan penyuluhan dan pemicuan, substansi materi dari penyuluhan dan pemicuan merupakan rekayasa yang lebih dititikberatkan pada aspek afektif dengan menstimuli perasaan dan emosional target sasaran. $\mathrm{Hal}$ ini dimaksudkan agar respon evaluatif dalam bentuk penilaian baik dan buruk lebih mudah dan cepat terbentuk, setelah aspek afektif ini dikondisikan kemudian substansi materi bisa berlanjut dengan menyasar pada objek kognitif (pengetahuan dan kepercayaan) dan konatif (tindakan).

Adapun metode atau jenis intervensi yang paling efektif digunakan adalah pemicuan dibandingkan penyuluhan. Hal ini sesuai dengan digalakkaannya program pemicuan yang prosesnya tidak hanya dilaksanakan di kelasa dalam bentuk transformasi pengetahuan satu arah. Pada intervensi pemicuan, sasaran akan dilibatkan atau melihat langsung permasalahan BABS di lapangan sehingga dalam proses tersebut target sasaran dapat merasakan, mencium, melihat dan mendengar sendiri hal hal yang kurang baik dan menjijikkan jika harus tetap melakukan BABS di lingkungannya.

Penyuluhan dan pemicuan merupakan pendekatan promosi kesehatan yang efektif dalam merubah sikap responden karena terjadi perubahan nilai rata rata sikap sebelum penyuluhan, setelah penyuluhan, dan setelah pemicuan. Penyuluhan dan pemicuan adalah suatu proses mempengaruhi sikap, pendapat dan perilaku orang lain, baik secara verbal maupun nonverbal. Proses itu sendiri adalah setiap gejala atau fenomena yang menunjukkan suatu perubahan yang terus-menerus dalam konteks waktu, setiap pelaksanaan atau perlakuan secara terus-menerus.

Hasil penelitian sejalan dengan penelitian yang membuktikan bahwa model pemicuan lebih efektif dari pada penyuluhan terhadap kepemilikan jamban (Bardosh, 2015; Garn et al., 2017). Ada dua persoalan yang berkaitan dengan penggunaan proses, yakni persoalan dinamika, objek, dan persoalan penggunaan bahasa. Komunikasi dapat mendekatkan sikap individu dengan sikap individu lainnya, dan bisa pula menjauhkannya. Hal ini tergantung pada posisi awal individu tersebut dengan individu yang lainnya. Strategi komunikasi persuasi yang baik, tidak bisa dikembangkan sampai seseorang mengetahui apakah sikap tertentu yang dilakukan oleh seorang persuadee membantu dalam 
penyesuaian, pertahanan ego, pengekspresian nilai, dan sebuah fungsi pengetahuan.

Hasil penelitian di atas sejalan dengan pengertian dan fungsi penyuluhan dan pemicuan, sehingga memungkinkan responden tersebut mampu menyesuaikan atau mengadaptasikan diri dengan pemahamannnya tentang Stop BABS (MCA-Indonesia \& Kesehatan, 2015). Penyuluhan dan pemicuan memang perlu dilakukan, karenanya pada tahap awal pemberian informasi responden masih melakukan pengenalan sementara penyuluhan adalah proses pengenalan informasi dan pemicuan menjadi proses pemantapan sehingga responden mendapatkan materi informasi lengkap dan bukti-bukti material tentang BABS yang secara langsung direspons oleh masing-masing individu dan memberikan kesan yang lebih dalam.

Penyuluhan dan pemicuan juga berhubungan dengan permasalahan sosial, budaya, dan perkembangan selain permasalahan yang berkaitan dengan fisik, emosi, dan kelainan mental. Pada proses penyuluhan dan pemicuan terjadi pertemuan antara konselor dengan kliennya yang memungkinkan terjadinya dialog, dalam proses ini akan menimbulkan respon yang mendorong terjadinya penyelesaian masalah oleh diri klien sendiri (Venkataramanan, Crocker, Karon, \& Bartram, 2018). Pesan utama yang disampaikan pada proses dan pelaksanaan penyuluhan dan pemicuan terus diulang-ulang untuk meningkatkan kesan dan menanamkan ingatan, oleh karenanya keterampilan petugas dalam memberikan penyuluhan dan membentuk suasana pemicuan ditingkatkan dengan membekali petugas kesehatan dengan keterampilan dalam CLTS sehingga mampu menerjemahkan materi tentang kesehatan lingkungan khususnya terkait dengan BAB dan perilaku BABS melalui penyampaian yang menarik dan dikemas melalui pilihan redaksional yang mudah dipahami dan dingat. Untuk memenuhi kebutuhan tersebut perlu dilakukan pelatihan keterampilan dan kompetensi tenaga promosi kesehatan di lingkungan institusi kesehatan, dimulai dari tenaga promosi kesehatan di Puskesmas atau di lingkungan dinas kesehatan.

Upaya untuk meningkatkan kesadaran masyarakat atau responden untuk tidak melakukan kebiasan BABS perlu dilakukan melalui berbagai cara dan metode. Sebagai salah satu objek sasaran bidang kesehatan maka petugas kesehatan dituntut memiliki kemampuan untuk memberikan penyuluhan dan melaksanakan pemicuan melalui pelatihan yang tujuannya agar kemampuan komunikasi tenaga penyuluh meningkat. Peran tenaga kesehatan begitu besar dalam memecahkan problem kesehatan komunitas.

\section{SIMPULAN}

Penyuluhan dan pemicuan dapat mengubah sikap mereka secara keseluruhan, baik pada aspek kognitif, afektif dan konatif. Temuan penelitian ini menunjukkan bahwa pada kelompok kontrol meskipun terjadi perubahan sikap namun perbedaan perubahannya lebih kecil dibandingkan dengan kelompok intervensi.

\section{SARAN}

Saran dalam penelitian ini adalah melaksanakan kegiatan penyuluhan sebelum melakukan kegiatan pemicuan serta kegiatan ini perlu terus dilakukan dengan melibatkan kelompok kecil secara bergiliran. Untuk menunjang kegiatan tersebut diperlukan pelatihan dan pembekalan kepada petugas kesehatan dan tokoh masyarakat sekitar agar memiliki kredibilitas dan kompetensi untuk memberikan penyuluhan dan menjadi fasilitator pemicuan tentang Stop BABS.

\section{DAFTAR PUSTAKA}

Annual Report Indonesia 2015. (2016). UNICEF INDONESIA.

Azwar, S. (2013). Sikap manusia: teori dan pengukurannya (edisi ke-2). Yogyakarta: Pustaka Pelajar.

Bardosh, K. (2015). Achieving "Total Sanitation" in Rural African Geographies: Poverty, Participation and Pit Latrines in Eastern Zambia. Geoforum, 66, 53-63.

https://doi.org/10.1016/j.geoforu 
m.2015.09.004

Chong, J., Abeysuriya, K., Hidayat, L., Sulistio, H., \& Willetts, J. (2016). Strengthening Local Governance Arrangements for Sanitation: Case Studies of Small Cities in Indonesia. Aquatic Procedia, 6, 64-73.

https://doi.org/10.1016/j.aqpro.2 016.06 .008

Crano, W. D., \& Prislin, R. (Eds.). (2008). Attitudes and Attitude Change. Madison Avenue: Psychology Press. Retrieved from http://www.ghbook.ir/index.php?

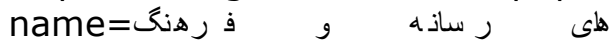
\& ذوي ن ن adonline\&book_id $=13650$ \&page $=$ 73\&chkhashk =ED9C9491B4\&Item $\mathrm{id}=218 \&$ lang $=$ fa\&tmpl=componen $\mathrm{t}$

Csapó, J., \& Magyar, A. (2010). Psychology of persuasion. Psychology of Persuasion, 1-191. https://doi.org/10.1037/13040018

Ekawati, C., Agustina, -, Dukabaen, O., \& Telan, A. B. (2017). The Influence of the $5 A^{\prime}$ 's Intervention towards Teenagers Attitude in Consuming Liquor at Kupang City. International Research Journal of Engineering, IT \& Scientific Research, 3(5), 53. https://doi.org/10.21744/irjeis.v3 i5. 541

Freeman, M. C., Garn, J. V., Sclar, G. D., Boisson, S., Medlicott, K., Alexander, K. T., ... Clasen, T. F. (2017). The impact of sanitation on infectious disease and nutritional status: A systematic review and meta-analysis. International Journal of Hygiene and Environmental Health, 220(6), 928-949. https://doi.org/10.1016/j.ijheh.2 017.05 .007

Garn, J. V., Sclar, G. D., Freeman, M. C., Penakalapati, G., Alexander, K. T., Brooks, P., ... Clasen, T. F. (2017). The impact of sanitation interventions on latrine coverage and latrine use: A systematic review and meta-analysis. International Journal of Hygiene and Environmental Health,
220(2), 329-340. https://doi.org/10.1016/j.ijheh.2 016.10.001

Grojec, A. (2015). Progress on Sanitation and Drinking Water (2015 Update and MDG Assessment). Switzerland: UNICEF and World Health Organization. Retrieved from http://www.who.int/water_sanitat ion_health/publications/jmp2015-update/en/

Hou, S.-I. (2014). Health Education: Theoretical Concepts, Effective Strategies and Core Competencies. Health promotion practice.

https://doi.org/10.1177/1524839 914538045

Laporan Hasil Riset Kesehatan Dasar (Riskesdas) Indonesia tahun 2018. (2018). Riset Kesehatan Dasar 2018.

Laporan Kemajuan Akses Sanitasi. (2019). Jakarta: Kementerian Kesehatan RI. Retrieved from http://monev.stbm.kemkes.go.id/

Laporan Kemajuan ODF. (2019). Kementerian Kesehatan RI. Retrieved from http://monev.stbm.kemkes.go.id/

Maulana, H. D. (2007). Promosi Kesehatan. (E. K. Yudha, Ed.). Jakarta: Penerbit Buku Kedokteran EGC.

MCA-Indonesia, \& Kesehatan, K. R. I. (2015). Pedoman Pelaksanaan Sanitasi Total Berbasis Masyarakat. Millennium Challenge A Ccount - Indonesia, (21), 16.

Nandi, A., Megiddo, I., Ashok, A., Verma, A., \& Laxminarayan, R. (2017). Reduced burden of childhood diarrheal diseases through increased access to water and sanitation in India: A modeling analysis. Social Science and Medicine, 180, 181-192. https://doi.org/10.1016/j.socscim ed.2016.08.049

Novotný, J., Humňalová, H., \& Kolomazníková, J. (2018). The social and political construction of latrines in rural Ethiopia. Journal of Rural Studies, 63(August), 157-167.

https://doi.org/10.1016/j.jrurstud 
.2018 .08 .003

Sharma, M., \& Romas, J. A. (2012). Theoretical Foundations of Health Education and Health Promotion. Ontario: Jones \& Bartlett Learning International.

Steele, R. (2019). Progress on Household Drinking Water, Sanitation and Hygiene 20002017. New York: WHO/UNICEF Joint Monitoring Programme for Water Supply and Sanitation (JMP).

Venkataramanan, V., Crocker, J., Karon, A., \& Bartram, J. (2018). Community-led total sanitation: A mixed-methods systematic review of evidence and its quality. Environmental Health Perspectives, 126(2). https://doi.org/10.1289/EHP1965

WHO. (2016). World Health Organization, 44(1), 23-63. https://doi.org/10.1183/0903193 6.00188313

Yulyani, V., Nuryani, D. D., \& Kurnia, D. (2019). Latrine Use And Associated Factors Among Rural Community In Indonesia. Malaysian Journal of Public Health Medicine, 19(1), 143-151. https://doi.org/http://10.0.20.16 1/zenodo.3375462 